\title{
CORRESPONDENCE
}

\section{Sodium and water homeostasis in children admitted with acute appendicitis: a prospective study}

Pediatric Research (2019) 86:5-8; https://doi.org/10.1038/s41390019-0353-4

\section{To the Editor}

In 2011 we began a randomized clinical trial (ISRCTN 43896775) to evaluate the safety and efficacy of near-isotonic compared with hypotonic fluid therapy in maintaining postoperative plasma sodium concentration $\left(\mathrm{P}_{\mathrm{Na}}\right)$ within the normal range. ${ }^{1}$ During the screening period, post-surgery, most patients displayed hyponatremia. Since normal $\mathrm{P}_{\mathrm{Na}}$ levels were an inclusion criterion, the trial was prematurely terminated due to poor accrual. ${ }^{1}$ We hypothesized that they may have had high circulating plasma levels of the antidiuretic hormone arginine-vasopressin (AVP) and that the prescription of intravenous hypotonic fluid therapy may have been a contributing factor to their hyponatremia. ${ }^{2}$ Consequently, we revised our local recommendations for fluid therapy (vide infra).

With this background, and considering that acute appendectomy is the most frequent pediatric operative procedure, ${ }^{3}$ the main aim of this prospective observational single-center cohort study in children was to evaluate the changes in $P_{\mathrm{Na}}$ from hospital admission to the end of surgery in the actual clinical setting. Since the pathophysiology of sodium and water homeostasis in the preoperative period is relatively unexplored, ${ }^{4,5}$ we also investigated the renal handling of sodium, as well as key hormones involved in sodium and water homeostasis.

This study was conducted in Sweden, from 31 May 2016 to 4 July 2017. Ethical approval was given by the Ethical Review Board in Stockholm (2016/181-31/2). This study protocol was registered at the Australian New Zealand Clinical Trial Registry (ANZCTR 12617000047392). All parents provided voluntary written informed consent for their children to participate in this study.

During the study period, 221 previously healthy children were admitted for suspected appendicitis. Since the enrollment of potential eligible participants was limited to the shift when our dedicated study team was working, 118 patients were not asked to participate, 7 declined participation, and 9 had been enrolled in another study. Eighty-seven children accepted participation, with 7 of these not receiving surgery and 28 excluded due to incomplete laboratory data. Our study population consisted of 52 children ( 35 males). All the patients fasted from admission until surgery and had postoperative histologically verified appendicitis: phlegmonous in 29 cases, gangrenous in 14 cases and perforated in 9 cases. $^{6}$

On admission, our patients displayed symptoms such as abdominal pain, fever, nausea and/or vomiting, and poor fluid intake. Since the degree of extracellular fluid deficit is difficult to assess only on clinical grounds, ${ }^{7}$ they were arbitrarily considered to have a mild dehydration, i.e., $5 \%$ loss of body weight. All patients received an intravenous infusion of $50 \mathrm{~mL} / \mathrm{kg}$ of Ringer's acetate solution $(131 \mathrm{mmol} / \mathrm{L}$ sodium, $4 \mathrm{mmol} / \mathrm{L}$ potassium, 2 $\mathrm{mmol} / \mathrm{L}$ magnesium, $110 \mathrm{mmol} / \mathrm{L}$ chloride, $30 \mathrm{mmol} / \mathrm{L}$ acetate;
Fresenius $\mathrm{Kabi}^{\circledR}$ ) over four hours. In 33 patients, this infusion was followed by a maintenance fluid and electrolyte therapy phase consisting of a hypotonic $0.23 \%$ normal sodium chloride ( 40 $\mathrm{mmol} / \mathrm{L}$ sodium, $20 \mathrm{mmol} / \mathrm{L}$ potassium, $60 \mathrm{mmol} / \mathrm{L}$ chloride; extempore solution) in $5 \%$ glucose solution until the start of the surgery. The fluid rate was decreased to $80 \%$ at the maintenance stage in order to minimize the undesirable effects of any unintended volume overload and fluid retention. ${ }^{8}$ The other 19 children did not receive the preoperative maintenance fluid and electrolyte therapy because they were operated on while receiving Ringer's acetate infusion or shortly afterwards. Anesthesia was induced with fentanyl, propofol or thiopental, and rocuronium and maintained with sevoflurane. Fluids were administered at anesthetist's discretion during surgery.

On admission (baseline), and directly after surgery $\mathrm{P}_{\mathrm{Na}}$, plasmapotassium $\left(\mathrm{P}_{\mathrm{K}}\right)$, plasma-chloride $\left(\mathrm{P}_{\mathrm{Cl}}\right)$, plasma-albumin $\left(\mathrm{P}_{\mathrm{Alb}}\right)$, plasma-creatinine $\left(\mathrm{P}_{\mathrm{cr}}\right)$, plasma-renin, plasma-aldosterone, plasma-AVP, serum-osmolality $\left(\mathrm{S}_{\mathrm{Osm}}\right)$, urine osmolality $\left(\mathrm{U}_{\mathrm{Osm}}\right)$, urine creatinine $\left(U_{\mathrm{cr}}\right)$, and urine sodium $\left(\mathrm{U}_{\mathrm{Na}}\right)$ were investigated. Plasma sodium was also analyzed at induction of anesthesia.

Routine laboratory tests were performed according to accredited hospital clinical laboratory procedure. The plasma-renin concentration was determined from EDTA-plasma that was incubated with plasma from a nephrectomized sheep followed by radioimmunoassay of angiotensin I through the antibodytrapping method as described by Poulsen and Jørgensen. ${ }^{9}$ Concentrations were measured by the rate of angiotensin I formation and standardized in terms of international units per liter (IU/L) based on the World Health Organization International Standard (ref. no. 68-356; National Institute for Biological Standards and Control, Hertfordshire, UK), with samples of 0.05 $\mathrm{IU} / \mathrm{L}$ included in every run of the plasma-renin assay. The interassay coefficient of variation was $6 \%$. Plasma-aldosterone was determined by ELISA (MS E-5200, LDN, Labor Diagnostika Nord, Germany). Human EDTA-plasma pool was used as an internal inter-assay standard. The inter-assay coefficient of variation was $4.3 \%$. Vasopressin levels were determined by radioimmunoassay as previously described, ${ }^{10}$ using a specific VP antibody (AB3096). ${ }^{11}$ Vasopressin was extracted from plasma using Sep-Pak ${ }^{\circledR}$ Plus C18 extraction cartridges (Waters Corporation, Milford, MA). The detection limit was $0.10 \mathrm{pg} / \mathrm{mL}$ plasma and the inter-assay coefficient of variation was $8 \%$.

The fractional excretion of sodium $\left(\mathrm{FE}_{\mathrm{Na}}\right)$ was calculated from a spot urine sample taken at baseline and at the end of surgery, as follows:

$\mathrm{FE}_{\mathrm{Na}}=\left[\left(\mathrm{U}_{\mathrm{Na}} / \mathrm{U}_{\mathrm{cr}}\right) /\left(\mathrm{P}_{\mathrm{Na}} / \mathrm{P}_{\mathrm{cr}}\right)\right] \times 100$

Statistical analyses were performed using IBM SPSS Statistics for Windows version 24 (IBM Corp, Armonk, NY). All continuous variables are presented as medians and interquartile ranges (IQR), unless otherwise stated. Paired $t$-test was carried out to compare individual differences, Pearson correlation coefficient was used to measure association between two variables, Fisher's exact test was 
Table 1. Characteristics of participants on admission (baseline) and at the end of surgery

\begin{tabular}{llll}
\hline Variable & Baseline $(n=52)$ & $\begin{array}{l}\text { End of Surgery } \\
(n=52)\end{array}$ & $p$-Value \\
\hline Weight $(\mathrm{kg})$ & $32(24-41.7)$ & - & - \\
$\mathrm{P}_{\mathrm{Na}}(\mathrm{mmol} / \mathrm{L})$ & $139(137-140)$ & $135(133-136)$ & $<0.001$ \\
$\mathrm{P}_{\mathrm{K}}(\mathrm{mmol} / \mathrm{L})$ & $3.9(3.7-4.1)$ & $4.0(3.8-4.4)$ & 0.039 \\
$\mathrm{P}_{\mathrm{Cl}}(\mathrm{mmol} / \mathrm{L})$ & $104(102-106)$ & $106(104-108)$ & $<0.001$ \\
$\mathrm{P}_{\text {Alb }}(\mathrm{g} / \mathrm{L})$ & $39(37-40)$ & $29(28-31)$ & $<0.001$ \\
$\mathrm{P}_{\mathrm{cr}}(\mu \mathrm{mol} / \mathrm{L})$ & $42(38-50)$ & $44(37-52)$ & 0.07 \\
$\mathrm{~S}-\mathrm{Osm}(\mathrm{mOsm} / \mathrm{kg})$ & $287(283-289)$ & $285(282-287)$ & 0.07 \\
$<285 \mathrm{mOsm} / \mathrm{kg}^{\mathrm{a}}$ & $n=16$ & $n=23$ & 0.2 \\
$\mathrm{P}-\mathrm{AVP}(\mathrm{pg} / \mathrm{mL})$ & $4.2(2.8-7.9)$ & $9(2.9-30.3)$ & $<0.001$ \\
$>5 \mathrm{pg} / \mathrm{mL}{ }^{\mathrm{b}}$ & $n=24$ & $n=34$ & 0.07 \\
$\mathrm{P}-\mathrm{Aldo}(\mathrm{pg} / \mathrm{mL})$ & $0.05(0.04-0.09)$ & $0.16(0.11-0.18)$ & $<0.001$ \\
$\mathrm{P}-\mathrm{Renin}(\mathrm{IU} / \mathrm{L})$ & $58(35-124)$ & $235(124-378)$ & $<0.001$ \\
$\mathrm{U}-\mathrm{Osm}(\mathrm{mOsm} / \mathrm{kg})$ & $904(520-1077)$ & $395(319-644)$ & $<0.001$ \\
$\mathrm{FE}_{\mathrm{Na}}(\%)$ & $0.29(0.14-0.57)$ & $0.73(0.42-1.37)$ & $<0.001$ \\
$\quad<0.5 \%{ }^{\mathrm{c}}$ & $n=38$ & $n=14$ & $<0.0001$ \\
\hline
\end{tabular}

Results are presented as medians (IQRs) unless otherwise indicated $P_{N a}$ plasma sodium, $P_{K}$ plasma-potassium, $P_{C}$ plasma-chloride, $P_{A l b}$ plasmaalbumin, $P_{c r}$ plasma-creatinine, S-Osm serum-osmolality, $P$-AVP plasmavasopressin, $P$-Aldo plasma-aldosterone, P-renin plasma-reninm, U-Osm urine osmolality, $F E_{\mathrm{Na}}$ fractional excretion of sodium

${ }^{a}$ Denotes number of participants $(n)$ with serum hypo-osmolality

${ }^{\mathrm{b}}$ Denotes number of participants $(n)$ with P-AVP levels expected to produce maximum antidiuresis (13)

'Denotes number of participants $(n)$ with renal sodium retention

used to compare dichotomous variables, and analysis of variance (ANOVA) followed by the post-hoc Bonferroni test, was performed for multiple pair-wise comparisons. Two-tailed $p$ values less than 0.05 were considered statistically significant.

Participants had a median age of 9 (7-11) years. The median time lapse from admission until the end of the surgery was 13 (9.5-19.8) hours, with a surgery duration of $1.5(1.5-2)$ hours.

Table 1 shows baseline and at the end of surgery characteristics. There was a significant decrease in $\mathrm{P}_{\mathrm{Na}}, \mathrm{P}_{\mathrm{K}}, \mathrm{P}_{\mathrm{Alb}}$, and $\mathrm{U}_{\mathrm{Osm}}$, and a significant increase in $\mathrm{P}_{\mathrm{Cl}}, \mathrm{FE}_{\mathrm{Na}}, \mathrm{AVP}$, aldosterone and renin, respectively.

On admission, 8 patients displayed hyponatremia $\left(\mathrm{P}_{\mathrm{Na}}<135\right.$ $\mathrm{mmol} / \mathrm{L})$. Seventeen of the 44 children who were initially normonatremic on admission became hyponatremic at the end of surgery. The analysis of variance showed that mean $\mathrm{P}_{\mathrm{Na}}$ differed significantly between baseline, induction of anesthesia, and end of surgery $[F(1,51)=222207,926, p<0.001]$. Ten of the 17 patients that were hyponatremic at end of surgery had normonatremia at the induction of anesthesia. In total, 25 (48\%) patients were hyponatremic at the end of surgery and the degree of hyponatremia was mild, i.e., $\mathrm{P}_{\mathrm{Na}} \geq 130<135 \mathrm{mmol} / \mathrm{L}^{12}$

The median total fluid administered from admission until the induction of anesthesia was 1500 (1117-2274) mL; Ringer's acetate solution $1200(1000-1700) \mathrm{mL}(n=52)$ and $0.23 \%$ normal sodium chloride $567(332-724) \mathrm{mL}(n=33)$, respectively. There was no significant difference between the effect of infusing Ringer's acetate solution alone $(n=19)$ or followed by $0.23 \%$ normal sodium chloride $(n=33)$ on $\mathrm{P}_{\mathrm{Na}}$ levels at induction of anesthesia; median $\mathrm{P}_{\mathrm{Na}} 136$ (134-137) $\mathrm{mmol} / \mathrm{L}$ and 136 (133-137) $\mathrm{mmol} / \mathrm{L}$, respectively, $p=0.48$. Intraoperatively, 18 participants received Ringer's acetate solution whereas 34 received a hypotonic $0.4 \%$ normal sodium chloride $(70 \mathrm{mmol} / \mathrm{L}$ sodium, 45 $\mathrm{mmol} / \mathrm{L}$ chloride, $25 \mathrm{mmol} / \mathrm{L}$ acetate; B. Braun Melsungen AG,
Melsungen, Germany) in $2.5 \%$ glucose solution, accounting for $156(100-250) \mathrm{mL}$. The median volume of $0.9 \%$ saline solution (154 mmol/L sodium, $154 \mathrm{mmol} / \mathrm{L}$ chloride) used intraoperatively to administer medications, mainly antibiotics, was 160 (102-223) $\mathrm{mL}$. Overall, the median fluid volume administered intraoperatively was $292(200-410) \mathrm{mL}$.

Fifteen of the 17 patients that became hyponatremic and 15 of the 27 children that remained normonatremic at end of surgery received intraoperatively $0.4 \%$ normal sodium chloride, $p=0.044$.

No significant correlations were observed between AVP and $\mathrm{S}_{\mathrm{Osm}}$ and between AVP and $\mathrm{U}_{\text {Osm }}$ (Fig. 1a-d). At the end of surgery, patients with both low circulating AVP levels and with AVP concentrations $>5 \mathrm{pg} / \mathrm{mL}$, which would be expected to produce maximum antidiuresis in healthy human adults, ${ }^{13}$ showed low $\mathrm{FE}_{\mathrm{Na}}$ when urine was more concentrated (Fig. 1f, h). Supplemental Fig. 1S (online) shows relationships between aldosterone and renin and $\mathrm{FE}_{\mathrm{Na}}$ at baseline and at the end of surgery.

In agreement with previous pediatric studies conducted in surgical patients, ${ }^{2}$ our data show that acute non-osmotic stimuli played a pivotal role for AVP release, supported by a lack of a significant association between AVP and $\mathrm{S}_{\mathrm{Osm}}$ (Fig. 1a, b). Additionally, in line with former investigations, ${ }^{5}$ hypotonic fluid therapy may have significantly contributed to the observed decrease in $\mathrm{P}_{\mathrm{Na}}$, most likely due to impaired water excretion that in turn resulted in dilutional hyponatremia, ${ }^{14}$ as suggested by a decreased postoperative $\mathrm{P}_{\mathrm{Alb}}{ }^{15}$ The content of chloride in Ringer's acetate solution may have also accounted for the postoperative increase in $\mathrm{P}_{\mathrm{Cl}}$.

In hospitalized patients, low $\mathrm{FE}_{\mathrm{Na}}$ values indicate sodium retention by the kidneys as a mechanism to preserve extracellular fluid volume. ${ }^{16,17}$ Patients that are expected to respond to volume replacement are generally characterized by a $\mathrm{FE}_{\mathrm{Na}}$ of $<0.5 \% .{ }^{16,17}$ According to the $\mathrm{FE}_{\mathrm{Na}}$ measurements obtained on admission and at the end of surgery, our data suggest that the majority of our patients moved from a volume-depleted to a non-hypovolemic state (Table 1). However, contrary to what might be expected, we did not observe a decrease in renin and aldosterone levels after surgery (Table 1 and Fig. 1S). ${ }^{18}$ This may imply a sympathetic nerve activation associated with surgical trauma, ${ }^{19}$ and not necessarily a lack of response to fluid therapy. This reasoning is furthered by the lack of significant associations observed between aldosterone and renin and $\mathrm{FE}_{\mathrm{Na}}$ at the end of surgery (Fig. 1S, B and D). Our results should be interpreted in the context of inappropriately high AVP levels. In healthy human adults, without previous water loading, the acute administration of desmopressin, a potent vasopressin receptor 2 agonist, not only increased urine osmolality but also reduced sodium excretion, ${ }^{20}$ whereas high hydration facilitates sodium excretion. ${ }^{21}$ After fluid therapy, we noted that as $\mathrm{FE}_{\mathrm{Na}}$ increased, the osmolality of urine decreased (Fig. 1f, h). In addition, this was accompanied by a significant increase in $\mathrm{FE}_{\mathrm{Na}}$ (Table 1). According to the postoperative clinical assessment, none of the participants were regarded as dehydrated (data not shown). Taken together, these results may indicate that a large number of patients were not volume-depleted after surgery. However, a limitation of this study is the lack of assessment of participants' weight after surgery and of urinary output. This may hamper the interpretation of patients' hydration status.

We also noted that the degree of water retention in some patients with high AVP levels appeared to decline as they became euvolemic (Fig. 1h). This data raises the question whether this observation can be regarded as an escape of the antidiuretic effect of $A V P,{ }^{22}$ aiming at stabilizing $\mathrm{P}_{\mathrm{Na}}$ levels. Recently published evidence-based clinical practice guidelines indicate that prescribing isotonic maintenance intravenous fluid therapy with appropriate potassium chloride and dextrose instead of hypotonic solutions provides more benefit than harm for most children in the surgical postoperative and medical acute-care setting. ${ }^{5}$ The largest published randomized clinical trial demonstrating that the 

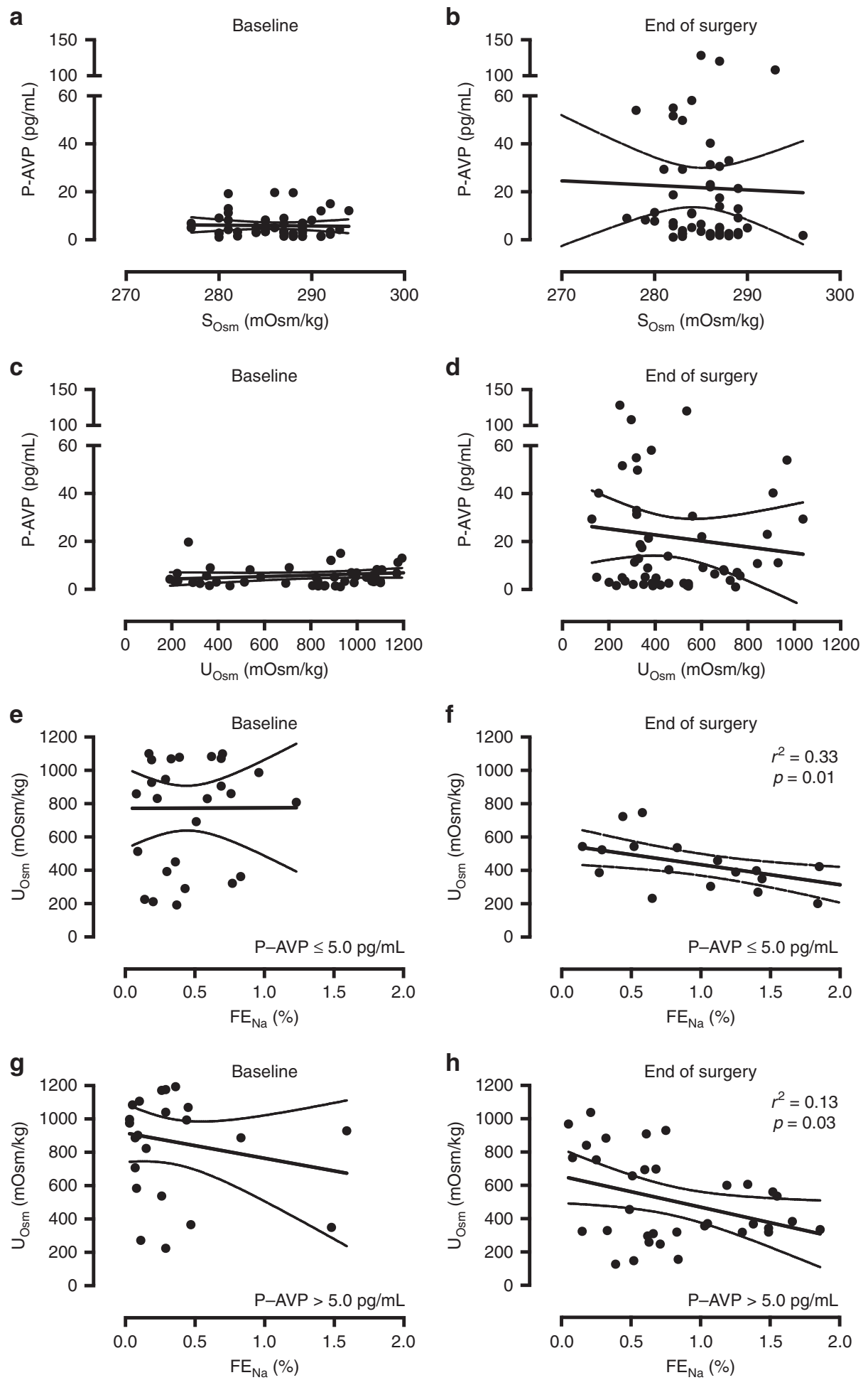

Fig. 1 Baseline and at the end of surgery relationships between plasma arginine-vasopressin ( $P$-AVP) and serum-osmolality $\left(\mathrm{S}_{\mathrm{O} \text { sm }}\right)(\mathbf{a}$, $\mathbf{b})$, between P-AVP and urine osmolality $\left(\mathrm{U}_{\mathrm{Osm}}\right)(\mathbf{c}, \mathbf{d})$, and between $\mathrm{U}_{\mathrm{Osm}}$ and fractional excretion of sodium ( $\left(\mathrm{FE}_{\mathrm{Na}}\right)$ in patients with P-AVP $\leq 5$ and $>5 \mathrm{pg} / \mathrm{mL}$ at baseline $(\mathbf{e}, \mathbf{g})$ and at the end of surgery $(\mathbf{f}, \mathbf{h})$, respectively

use of isotonic solutions as compared to hypotonic solutions, for maintenance intravenous fluid therapy is associated with a significantly lower risk of hyponatremia in hospitalized children identified only a few patients with asymptomatic severe hyponatremia in each treatment arm. ${ }^{23}$

In summary, our results add to the growing body of evidence that hypotonic fluid therapy contributes to the acute decrease in $\mathrm{P}_{\mathrm{Na}}$ in hospitalized children and provides additional information on sodium and water homeostasis before and during surgery. Finally, further research is warranted to elucidate any potential mechanisms that might prevent patients with mild/moderate hyponatremia and high circulating AVP levels from further decreases in their $P_{\mathrm{Na}}$ levels. 


\section{ACKNOWLEDGEMENTS}

The authors would like to thank all the participating children and their parents. We would also like to thank Marie-Christin Johansson, Emma Mellgren, and Maria Westerståhl for logistic assistance during the study, Shukri Omar and Jesper Keisu for the laboratory sample management, Susanne Hansen and Gitte Kitlen for excellent technical assistance, and Bodil Kristensen and Peter Bie for their valuable advice concerning the arginine-vasopressin assay.

\section{FUNDING}

M.A. and J.F.S. received grants from Sällskapet Barnvård and the Crown Princess Lovisa's Foundation.

\section{AUTHOR CONTRIBUTIONS}

R.T.K. and U.F. conceptualized and designed the study. R.T.K. carried out the statistical analysis, wrote the initial manuscript draft, and takes responsibility for the integrity and the accuracy of the data analysis. Acquisition, analysis, or interpretation of the data: all authors. Critical revision of the manuscript for important intellectual content: all authors.

\section{ADDITIONAL INFORMATION}

The online version of this article (https://doi.org/10.1038/s41390-019-0353-4) contains supplementary material, which is available to authorized users.

Competing interests: The authors declare no competing interests.

Publisher's note: Springer Nature remains neutral with regard to jurisdictional claims in published maps and institutional affiliations.

Ulf Lindestam ${ }^{1,2}$, Urban Fläring ${ }^{1,2}$, Markus Almström ${ }^{3,4}$, Andreas Andersson ${ }^{1,2}$, Jan F. Svensson ${ }^{3,4}$, Pia Malmquist ${ }^{{ }^{\prime}}$, Johannes Jacks ${ }^{1}$, Per-Arne Lönnqvist ${ }^{1,2}$, Boye L. Jensen ${ }^{6}$, Mattias Carlström ${ }^{2}$ and Rafael T. Krmar ${ }^{2}$

${ }^{1}$ Department of Pediatric Perioperative Medicine and Intensive Care, Astrid Lindgren Children's Hospital, Karolinska University Hospital, Stockholm, Sweden; ${ }^{2}$ Department of Physiology and Pharmacology (FYFA), Karolinska Institutet, Stockholm, Sweden; ${ }^{3}$ Department of Paediatric Surgery, Astrid Lindgren Children's Hospital, Karolinska University Hospital, Stockholm, Sweden; ${ }^{4}$ Department of Women's and Children's Health, Karolinska Institutet, Stockholm, Sweden;

${ }^{5}$ Department of Pediatric Emergency Medicine, Astrid Lindgren Children's Hospital, Karolinska University Hospital, Stockholm, Sweden and ${ }^{6}$ Department of Cardiovascular and Renal Research, Institute of Molecular Medicine, University of Southern Denmark,

Odense, Denmark Correspondence: Rafael T. Krmar (rafael.krmar@ki.se)

\section{REFERENCES}

1. Flaring, U. et al. The efficacy of hypotonic and near-isotonic saline for parenteral fluid therapy given at low maintenance rate in preventing significant change in plasma sodium in post-operative pediatric patients: protocol for a prospective randomized non-blinded study. BMC Pediatr. 11, 61 (2011).

2. Oh, G. J. \& Sutherland, S. M. Perioperative fluid management and postoperative hyponatremia in children. Pediatr. Nephrol. 31, 53-60 (2016).

3. Somme, S., Bronsert, M., Morrato, E. \& Ziegler, M. Frequency and variety of inpatient pediatric surgical procedures in the United States. Pediatrics 132, e1466-e1472 (2013)

4. McNab S. et al. Isotonic versus hypotonic solutions for maintenance intravenous fluid administration in children. Cochrane Database Syst Rev. 12, 1-62 (2014).

5. Feld L. G. et al. Clinical Practice Guideline: Maintenance Intravenous Fluids in Children. Pediatrics 142, 1-14 (2018).

6. Carr, N. J. The pathology of acute appendicitis. Ann. Diagn. Pathol. 4, 46-58 (2000).

7. Chung, H. M., Kluge, R., Schrier, R. W. \& Anderson, R. J. Clinical assessment of extracellular fluid volume in hyponatremia. Am. J. Med. 83, 905-908 (1987).

8. Hatherill, M. Rubbing salt in the wound. Arch. Dis. Child. 89, 414-418 (2004).

9. Poulsen, K. \& Jorgensen, J. An easy radioimmunological microassay of renin activity, concentration and substrate in human and animal plasma and tissues based on angiotensin I trapping by antibody. J. Clin. Endocrinol. Metab. 39, 816-825 (1974).

10. Bie, P. \& Sandgaard, N. C. Determinants of the natriuresis after acute, slow sodium loading in conscious dogs. Am. J. Physiol. Regul. Integr. Comp. Physiol. 278, R1-r10 (2000).

11. Emmeluth, C., Drummer, C., Gerzer, R. \& Bie, P. Natriuresis in conscious dogs caused by increased carotid $[\mathrm{Na}+]$ during angiotensin II and aldosterone blockade. Acta Physiol. Scand. 151, 403-411 (1994).

12. Spasovski, G. et al. Clinical practice guideline on diagnosis and treatment of hyponatraemia. Eur. J. Endocrinol. 170, G1-G47 (2014).

13. Baylis, P. H. Osmoregulation and control of vasopressin secretion in healthy humans. Am. J. Physiol. 253, R671-R678 (1987).

14. Robertson, G. L. Antidiuretic hormone. Normal and disordered function. Endocrinol. Metab. Clin. North. Am. 30, 671-694 (2001). vii.

15. Lobo, D. N. et al. Dilution and redistribution effects of rapid 2-litre infusions of $0.9 \%(\mathrm{w} / \mathrm{v})$ saline and $5 \%(\mathrm{w} / \mathrm{v})$ dextrose on haematological parameters and serum biochemistry in normal subjects: a double-blind crossover study. Clin. Sci. (Lond.) 101, 173-179 (2001).

16. Schrier, R. W. Diagnostic value of urinary sodium, chloride, urea, and flow. J. Am. Soc. Nephrol. 22, 1610-1613 (2011).

17. Tam, R. K., Wong, H., Plint, A., Lepage, N. \& Filler, G. Comparison of clinical and biochemical markers of dehydration with the clinical dehydration scale in children: a case comparison trial. BMC Pediatr. 14, 149 (2014).

18. Gerigk, M., Gnehm, H. E. \& Rascher, W. Arginine vasopressin and renin in acutely ill children: implication for fluid therapy. Acta Paediatr. 85, 550-553 (1996).

19. Desborough, J. P. The stress response to trauma and surgery. Br. J. Anaesth. $\mathbf{8 5}$, 109-117 (2000).

20. Bankir, L., Fernandes, S., Bardoux, P., Bouby, N. \& Bichet, D. G. Vasopressin-V2 receptor stimulation reduces sodium excretion in healthy humans. J. Am. Soc. Nephrol. 16, 1920-1928 (2005).

21. Choukroun, G., Schmitt, F., Martinez, F., Drueke, T. B. \& Bankir, L. Low urine flow reduces the capacity to excrete a sodium load in humans. Am. J. Physiol. 273, R1726-R1733 (1997).

22. Verbalis, J. G. Whole-body volume regulation and escape from antidiuresis. Am. J. Med. 119, S21-S29 (2006).

23. McNab, S. et al. $140 \mathrm{mmol} / \mathrm{L}$ of sodium versus $77 \mathrm{mmol} / \mathrm{L}$ of sodium in maintenance intravenous fluid therapy for children in hospital (PIMS): a randomised controlled double-blind trial. Lancet 385, 1190-1197 (2015). 